\title{
Two Cases With Cushing Syndrome: What an Anesthesiologist Should Know
}

\author{
Rudin Domia, ${ }^{\text {a }}$, Hektor Sula ${ }^{\mathrm{a}}$, Mustafa Xhani ${ }^{\mathrm{b}}$, Aurel Janko ${ }^{\mathrm{b}}$, Bilbil Hoxha ${ }^{\mathrm{b}}$, \\ Rezart Xhani ${ }^{b}$, Herion Dredha ${ }^{b}$
}

\begin{abstract}
Cushing syndrome is a multietiologic clinical situation, resulting in several features like obesity, hyperglycemia, hypertension, proximal muscle weakness, skin thinning, menstrual irregularities, buffalo hump, and purple striae. In perioperative period the anesthesiologist must deal with difficult ventilation and intubation, hemodynamic disturbances, volume overload and hypokalemia, glucose intolerance and diabetes, maintaining the blood cortisol level and preventing the glucocorticoid deficiency. This syndrome is quite rare and its features make these patients very difficult to the anaesthesiologist.
\end{abstract}

Keywords: Adrenalectomy; Cushing syndrome

\section{Introduction}

Cushing's syndrome (CS) is associated with reduced life expectancy and increased mortality mostly due to cardiovascular disease. The features of this syndrome are central obesity, moon facies, facial plethora, supraclavicular fat pads, buffalo hump, and purple striae. Hyperglycemia, hypertension, proximal muscle weakness, skin thinning, menstrual irregularities, amenorrhea, and osteopenia are present as well. According to these features anesthetic management is difficult and presents a challenge to the operating team.

Manuscript accepted for publication March 25, 2011

\footnotetext{
a Department of Anesthesiology, Intensive Care, Emergency and Toxicology, University Hospital Center "Mother Theresa", Tirana, Albania

bDepartment of Urology, University Hospital Center "Mother Theresa", Tirana, Albania

${ }^{\mathrm{c}}$ Corresponding author: Rudin Domi, Str Rruga e Dibres, 370, Tirana, Albania. Email: rudilaureta@hotmail.com
}

doi: $10.4021 /$ jem $5 \mathrm{w}$

\section{Case Reports}

\section{Case 1}

M.B., a 38-year-old woman (body weight $90 \mathrm{~kg}$, height 165 $\mathrm{cm}$, BMI 33, ASA I) without significant previous medical history, was consulted by an endocrinologist because of hyperglycemia, hypertension, menstrual irregularities, and hirsutism also. CS was suspected. She underwent an angioCT, ultrasound examination, and blood levels of cortisol and ACTH, during which a left adrenal hyperplasia was verified (Fig. 1). The cortisol and ACTH blood levels were $929 \mathrm{ng} /$ $\mathrm{ml}(28$ - 120) and $21.6(20$ - 113) respectively. Clinical assessment, chest $\mathrm{x}$-ray and electrolytes findings were normal. Preoperative hypertension was treated with metoprolol and valsartan, whereas hyperglycemia (168 - $173 \mathrm{mg} / \mathrm{dl})$ with insulin regimen. The evaluation of possible difficult intubation or ventilation was performed, with unremarkable results. The patient was premedicated with oral Diazepam $10 \mathrm{mg}$ the night before the surgery and morphine sulfate $10 \mathrm{mg}$ intra-

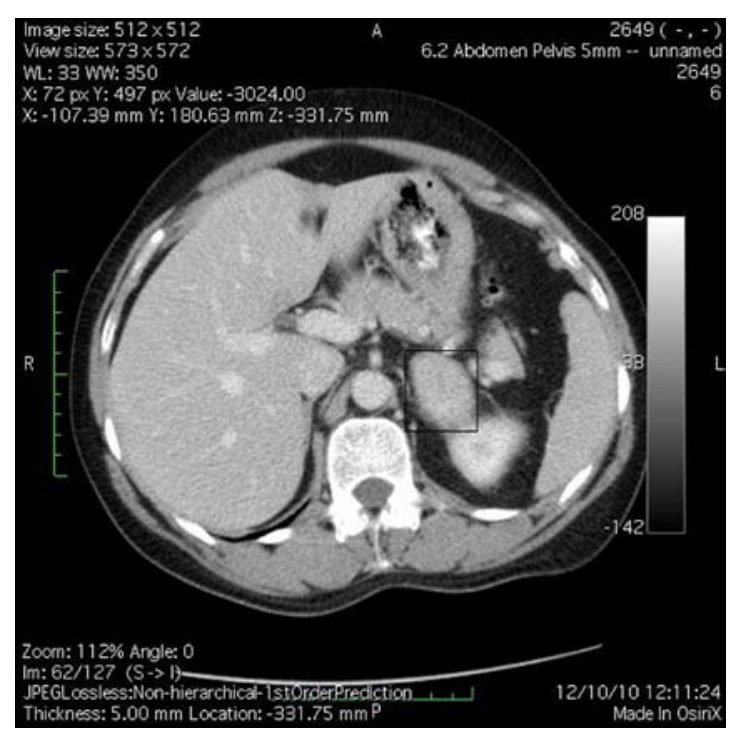

Figure 1. Angio-CT demonstrated left adrenal hyperplasia. 


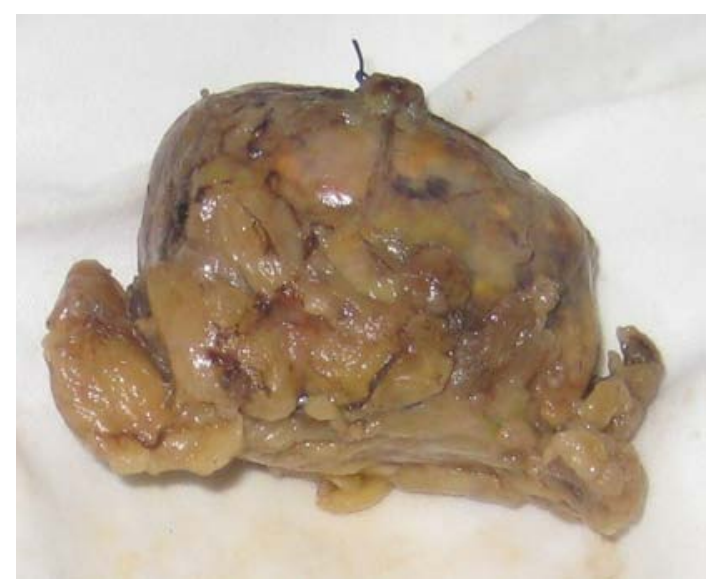

Figure 2. Excised left adrenal gland.

muscularly 30 minutes before the induction of anesthesia, and continued with all the preoperative treatment including ketokonazol $800 \mathrm{mg} / \mathrm{d}$. Preoperative period was uneventful. In operating room after peripheral venous cannula was inserted, right radial artery and right internal jugular vein were cannulated with $20 \mathrm{G}$ venous catheter $7.5 \mathrm{~F}$ central venous catheter. The anesthesia's induction was made with Fentanyl $5 \mathrm{mcg} / \mathrm{kg}$, Propofol $2 \mathrm{mg} / \mathrm{kg}$, cis-atracurium $0.15 \mathrm{mg} / \mathrm{kg}$. Monitoring included invasive arterial monitoring, central venous pressure, ECG, temperature, urine output, end-Tidal carbon dioxide, and blood cortisol and sugar levels and electrolytes. The anesthesia was maintained with sevoflurane, profofol infusion, fentanyl and cis-Atracurium as needed. An open radical left adrenalectomy (Fig. 2) was performed, and after that $100 \mathrm{mg}$ endovenous hydrocortisone was administered. Postoperatively the hyperglycemia was corrected, and no more insulin was needed. Ketokonazol was discontinued

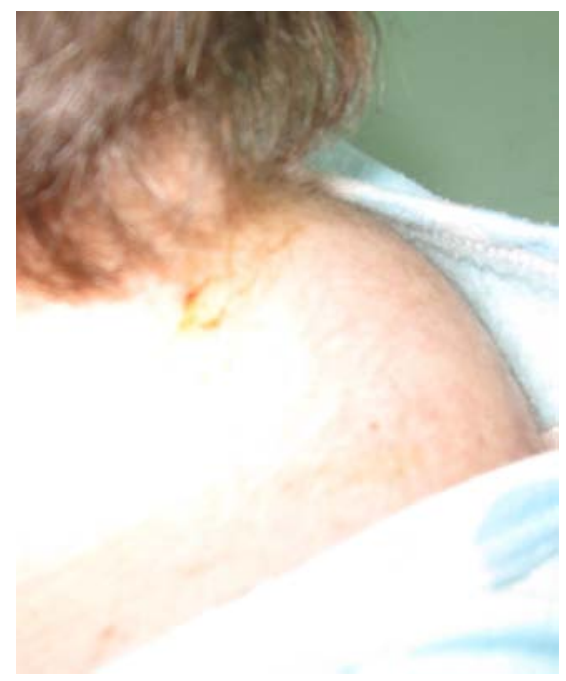

Figure 3. Buffalo hump.

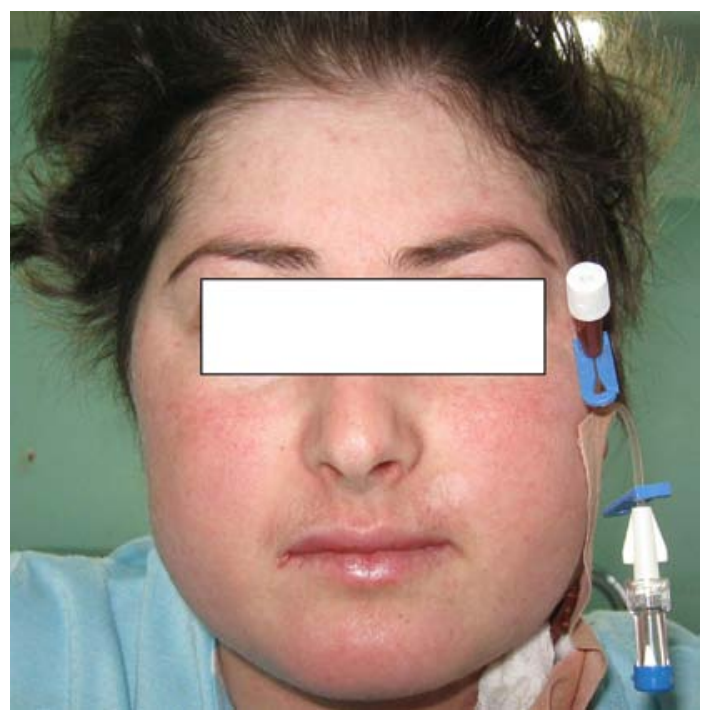

Figure 4. Moon facies.

also. The hypertension also was stabilized and only a small dose of metoprolol was necessary. Cortisol level was $98 \mathrm{ng} /$ $\mathrm{ml}(28$ - 120), under oral hydrocortisone. There was no electrolyte disturbance. The surgery and postoperative period were uneventful and the patient was discharged in the 5th postoperative day referring to the endocrinologist.

\section{Case 2}

J.S., a 22-year-old woman (body weight $45 \mathrm{~kg}$, height 160 $\mathrm{cm}$, BMI 18, ASA I) without significant previous medical history (expect menstrual irregularities), was consulted by an orthopedic surgeon because of pelvic bones fractures. No previous traumatic medical history was reported. The patient was treated conservatory, but no effort was made to diagnose the etiology of her fractures. Physical examination was unremarkable. She was discharged and after this she manifested

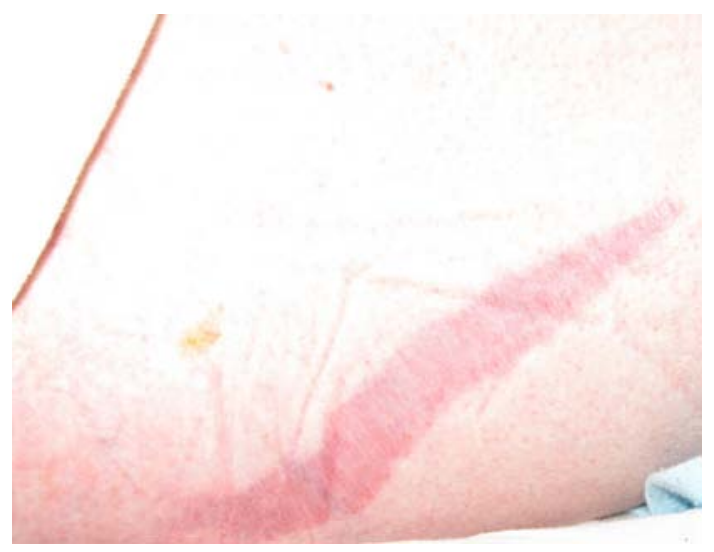

Figure 5. Purple striae on skin. 


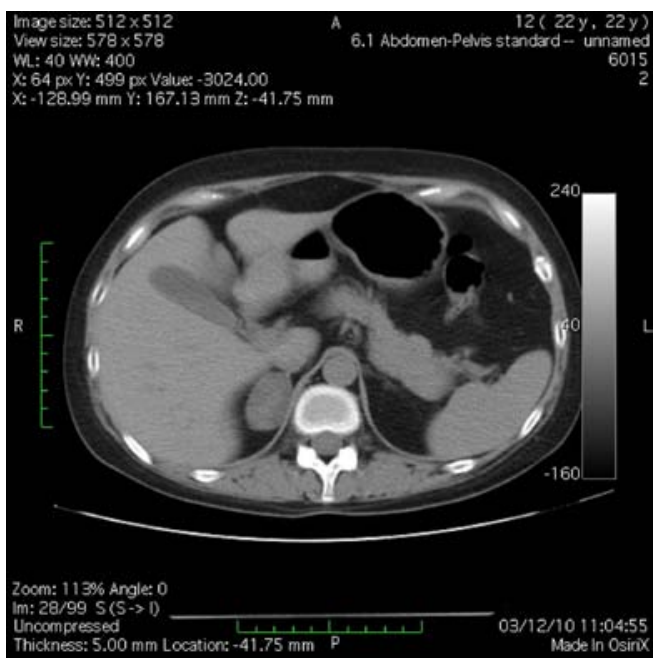

Figure 6. Angio-CT demonstrated right adrenal hyperplasia.

buffalo hump (Fig. 3), moon facies (Fig. 4), striae (Fig. 5), hirsutism, a mild hypertension, and glucose intolerance also. Endocrinologist's consult suspected a CS. Right adrenal hyperplasia was confirmed by angio-CT (Fig. 6) and ultrasound examination, and blood level of cortisol and ACTH. The blood cortisol and ACTH levels were $219 \mathrm{ng} / \mathrm{ml}(28$ $120)$ and $23.7(20$ - 113) respectively. The other examinations were normal. Preoperative hypertension was treated with spironolactone. The evaluation of possible difficult intubation or ventilation was performed, with unremarkable results. The patient was premedicated with oral Diazepam 10 $\mathrm{mg}$, and continued with all the preoperative treatment including ketokonazol $600 \mathrm{mg} / \mathrm{d}$. Preoperative period was uneventful. In operating room after peripheral venous cannula was inserted, right radial artery and right internal jugular vein were cannulated. The anesthesia's induction was made with Fentanyl $3 \mathrm{mcg} / \mathrm{kg}$, Propofol $2 \mathrm{mg} / \mathrm{kg}$, cis-atracurium 0.15 $\mathrm{mg} / \mathrm{kg}$. Monitoring included standard monitoring, invasive arterial monitoring, blood cortisol and sugar levels and electrolytes. The anesthesia was maintained with sevoflurane, profofol infusion, fentanyl and cis-Atracurium as needed. An open radical right adrenalectomy was performed, and after that $100 \mathrm{mg}$ endovenous hydrocortisone was administered. Postoperative cortisol level was $98 \mathrm{ng} / \mathrm{ml}(28$ - 120), under oral hydrocortisone. There was no electrolyte disturbance. The surgery and postoperative period were uneventful and the patient was discharged in the 4th postoperative day referring to the endocrinologist.

\section{Discussion}

Cushing's syndrome has a multifactorial etiology. Administration of exogenous steroids may lead to the development of Cushing's syndrome. Symptoms of glucocorticoid excess generally occur with the administration of oral steroids, injections of steroids, inhalers and unguents as well [1]. Patients with diseases that respond to steroid therapy are especially likely to receive steroids and thus develop Cushing syndrome. Other causes are unilateral or bilateral adrenal hyperplasia, pituitary adenoma (Cushing Disease), and ectopic tissues that produce adrenocorticotropin releasing hormone (ACTH). Our patients had unilateral adrenal hyperplasia.

All the CS' clinical features were found in our patients. J.S. debuted with a nontraumatic pelvic bones fracture. Meanwhile the patient was visited by several physicians but nobody suspected CS. After she was discharged home, the clinical signs suggesting CS were developed. When we face such a strange and unexplained fracture and osteopenia, must take CS as a possible cause. M.B. debuted with all clinical features and diagnosing her was not difficult. The diagnosis must be completed with serum level of cortisol, ACTH, and dexamethasone suppression test. Our patients' diagnoses were confirmed by angio-CT and ultrasound examination.

There are similarities between Cushing's syndrome and the metabolic syndrome as both are characterized by central obesity, hypertension, insulin resistance, glucose intolerance, and dyslipidemia. There is a study that supports the view that unknown CS is not rare among patients with diabetes mellitus [2]. This is the first demonstration that screening for CS may be feasible at the clinical onset of diabetes in an unselected cohort of patients. Therefore, early diagnosis and treatment of CS may provide the opportunity to improve the prognosis of diabetes. Our patients had metabolic syndrome characterized by dyslipidemia, hyperglycemia, and hypokalemic metabolic alkalosis.

Several studies have demonstrated the concomitance of $\mathrm{CS}$ and several tumor diseases. There are reports in literature on the concurrent CS and pheochromocytoma [3, 4], sarcoidosis [5], pancreatic acinar cell carcinoma [6], pre-eclamptic findings [7], malignant gastrinoma [8], bronchial carcinoid lung tumor [9], pancreatic neuroendocrine tumor [10], Hippel-Lindau disease [10], or mesenteric neuroendocrine carcinoma [11]. Our patients had nothing of these associations.

It is well known that the patients suffering from CS tend to be volume overload and hypertensive, glucose intolerance and hyperglycemia, and hypokalemic metabolic alkalosis. Both patients had those problems, and we took care to maintain the stability. Patients undergoing adrenalectomy may require intraoperative glucocorticoid replacement, so we administered intraoperatively $100 \mathrm{mg}$ hydrocortisone succinate. The replacement continued in the postoperative period, guided by cortisol level. None of the patients had cortisol deficiency.

Patients suffering from CS also have muscle weakness and osteopenia. We took care to use minimum dose of muscle relaxants drugs, choosing cis-atracurium, a short actingplasma degradation drug. Positioning our patients was made carefully to avoid fractures and skin damages. 
Several possible respiratory complications may be faced. The mask ventilation may be difficult because of obesity. Hypoventilation may occur as a consequence of obesity and proximal muscle weakness, contributing to hypoxia and hypercarbia.

After adrenalectomy we must take care to prevent cortisol deficiency, to mobilize and activate the patient, and prevent atelectasis through respiratory exercises as well.

Laparoscopic adrenalectomy remains gold standard but Cushing's syndrome is associated with longer hospitalizations, more frequent major complications, and higher advanced care requirements, especially for bilateral adrenalectomy [12].

We conclude that CS presents a challenge to anesthesiologist. We must deal with the volume overload, hyperglycemia, hypokalemia, difficult airway and ventilation. Postoperatively we must take care to supplement the cortisol (guided by cortisol blood level), correct electrolyte disturbances and of course maintain stability of hemodynamics and blood sugar level.

\section{References}

1. Semiz S, Balci YI, Ergin S, Candemir M, Polat A. Two cases of Cushing's syndrome due to overuse of topical steroid in the diaper area. Pediatr Dermatol 2008;25(5):544-547.

2. Reimondo G, Pia A, Allasino B, Tassone F, Bovio S, Borretta G, Angeli A, et al. Screening of Cushing's syndrome in adult patients with newly diagnosed diabetes mellitus. Clin Endocrinol (Oxf) 2007;67(2):225-229.

3. Bayraktar F, Kebapcilar L, Kocdor MA, Asa SL, Yesil $\mathrm{S}$, Canda S, Demir T, et al. Cushing's syndrome due to ectopic CRH secretion by adrenal pheochromocytoma accompanied by renal infarction. Exp Clin Endocrinol Diabetes 2006;114(8):444-447.

4. Kumar M, Kumar V, Talukdar B, Mohta A, Khurana N. Cushing syndrome in an infant due to cortisol secreting adrenal pheochromocytoma: a rare association. J Pediatr Endocrinol Metab 2010;23(6):621-625.

5. Schaefer S, Meyer S, Brueck CC, Weber M, Luedecke D, Wagner HJ, Kann PH. Sarcoidosis following Cushing's syndrome: A report of two cases and review of the literature. Exp Clin Endocrinol Diabetes 2010;118(3):147150.

6. Illyes G, Luczay A, Benyo G, Kalman A, Borka K, Koves K, Racz K, et al. Cushing's syndrome in a child with pancreatic acinar cell carcinoma. Endocr Pathol 2007;18(2):95-102.

7. Delibasi T, Ustun I, Aydin Y, Berker D, Erol HK, Gul K, Unal M, et al. Early severe pre-eclamptic findings in a patient with Cushing's syndrome. Gynecol Endocrinol 2006;22(12):710-712.

8. Park SY, Rhee Y, Youn JC, Park YN, Lee S, Kim DM, Song SY, et al. Ectopic Cushing's syndrome due to concurrent corticotropin-releasing hormone (CRH) and adrenocorticotropic hormone (ACTH) secreted by malignant gastrinoma. Exp Clin Endocrinol Diabetes 2007;115(1):13-16.

9. Esfahani AF, Chavoshi M, Noorani MH, Saghari M, Eftekhari M, Beiki D, Fallahi B, et al. Successful application of technetium-99m-labeled octreotide acetate scintigraphy in the detection of ectopic adrenocorticotropin-producing bronchial carcinoid lung tumor: a case report. J Med Case Reports 2010;4:323.

10. Benitez Velazco A, Pacheco Capote C, Latre Romero JM. [Ectopic Cushing's syndrome caused by a functioning pancreatic neuroendocrine tumour in a patient with von Hippel-Lindau disease]. Rev Esp Med Nucl 2008;27(1):29-33.

11. Fasshauer M, Lincke T, Witzigmann H, Kluge R, Tannapfel A, Moche M, Buchfelder M, et al. Ectopic Cushing' syndrome caused by a neuroendocrine carcinoma of the mesentery. BMC Cancer 2006;6:108.

12. Kissane NA, Cendan JC. Patients with Cushing's syndrome are care-intensive even in the era of laparoscopic adrenalectomy. Am Surg 2009;75(4):279-283. 